\title{
Energy poverty in Spain: an income approach analysis
}

\author{
Maria T. Costa-Campi, Elisenda Jové-Llopis and Elisa Trujillo-Baute ${ }^{1}$ \\ University of Barcelona \& Barcelona Institute of Economics, Chair of Energy \\ Sustainability
}

\begin{abstract}
This paper highlights the importance of approaching the energy poverty problem considering the income perspective. This approach is based on the economic analysis of the relationship between energy poverty, energy consumption and elements linked to household income. Robust conclusions are presented from the empirical analysis of statistical data to quantify and diagnose the problem of energy poverty in Spain, using econometric tools. Likewise, the relative importance of household income in the energy poverty problem is evaluated. The results reinforce the idea that energy poverty should be addressed, preferably, through the general social protection system, and that mechanisms to protect vulnerable consumers should be developed within the framework of the general welfare system. Conclusions emphasize the need for a profound deliberation on how to address energy poverty with cross-cutting public policies that, in addition to the elements directly linked to energy policy, act on the main determinants of energy poverty, fundamentally linked, directly or indirectly, to the income of households.
\end{abstract}

Keywords: energy poverty, Low Income High Cost, Spain

\footnotetext{
${ }^{1}$ Corresponding author: elisatrujillo@ub.edu
} 


\section{Introduction}

In recent years, political representatives and policy makers have shown growing concern for a particular aspect of poverty in the population that appears in the form of energy poverty. The debate in Europe about the problem of energy poverty is no exception. On the contrary, the explicit recognition by the various institutions of the European Union (EU) of the need to consider the economic, social, environmental and health consequences of energy poverty in the formulation of climate and energy policy is more present than ever (European Commission, 2016; Bouzarovski et al., 2012).

Due to there being progressively more evidence that in many countries of the European Union there are households with difficulties in maintaining an adequate temperature in the home given the level of family income and the consumption of other goods and services necessary for individual welfare (Pye et al., 2015; Legendre and Ricci, 2015; Buzar, 2016), a set of measures has been presented by the European Union to tackle energy poverty. In particular, in 2011, the European Social and Economic Committee (ESEC) proposed the adoption of a definition of energy poverty in all the EU, as well as the harmonisation of the existing statistics in order to evaluate the energy poverty situation in Europe rigorously. Along the same lines, in the latest proposed legislation, Clean energy for all Europeans (European Commission, 2016), three axes of activity focus the elaboration of actions to improve the conditions of consumers: empowerment, the improvement of information, and protection. It is exactly within this last axis of consumer protection where energy poverty is located, and which is to be confronted by a European strategy with soft policy instruments that have essentially materialised through the creation of the EU Energy Poverty Observatory (EPOV). The main objective of this institution, promoted by the ESEC, is to support and supervise the Member States in their activities countering energy poverty through communicating best practices in combatting this problem, as well as the production of statistics on energy poverty based on reliable and comparable data. In spite of recent efforts to try to explore the problem of energy poverty from a European perspective, the approaches adopted by Member States vary enormously as it is the national governments that are charged with defining the strategic lines of action. This has made the adoption of a well-defined framework at an EU level difficult. 
Although in recent years an important part of the academic literature has concentrated its efforts on defining and quantifying energy poverty (Besagni and Borgarello, 2019; DECC, 2016; Papada and Kaliampakos, 2018; Thomson and Snell, 2013), the identification and description of the determinants of energy poverty have been less studied up to this time. Understanding the determinants of income and expenditure in the population is fundamental for evaluating the potential that public policy can have in attempting to confront the problem of energy poverty. Along these lines, the main objective of this study is the empirical analysis of the problem of energy poverty in Spain from the angle of household income. This approach is based on an economic analysis of the relation between energy poverty, energy consumption and elements connected to household income. To carry out the econometric analysis an exhaustive sample has been used of more than 150,000 households extracted from the Spanish Household Budget Survey (HBS) for the period 2011-2017.

Along the same lines as in other EU countries, public policies to fight energy poverty in Spain are implemented at different levels of government. The main action lines are from the national government, the social tariffs for electricity (since 2009) and for heating (since 2018), and energy efficiency measures. Regional and local governments execute additional measures within their corresponding fields of action. The cost of the social tariff for electricity (a discount on the energy bill subject to specific conditions of the household) is a burden on retailers. Households enjoying the social tariff for electricity also receive the social tariff for heating, but unlike the first one, the cost of the last policy is covered by the national government budget. Regarding energy efficiency, the main policy is the national action plan for energy efficiency (2017-2020), which includes specific actions such as the dissemination of information on the available energy efficiency measures, as well as aid programs for the energy rehabilitation of buildings (called PAREER-CRECE $\left.{ }^{2}\right)^{3}$.

The results of this study show that the main factors that influence the probability that a Spanish household will be considered energy poor - unemployment, level of higher

\footnotetext{
2 These actions are funded through the National Energy Efficiency Fund, financially endorsed by mandatory energy savings from gas and electricity retailers, and from wholesale petroleum and liquefied petroleum gas products operators.

${ }^{3}$ Lakatos and Arsenopoulos, 2019 provide an overview of the existing financial instruments and successful schemes focused on facilitating the implementation of energy efficiency-related measures, in the context of addressing the problem of energy poverty in the EU and its adverse socio-economic effects.
} 
education and household composition - are closely related to the household income level. Factors related to the expenditure of the household - including energy efficiency-are also significant determinants of energy poverty, but with a smaller order of magnitude. These results reinforce the idea that energy poverty should preferably be tackled through the social protection system, and that the mechanisms to protect vulnerable consumers should be established within the framework of the general welfare system.

This study makes several contributions. First, the European part of the literature has notably concentrated on examining the rate of energy poverty in countries like the United Kingdom, where the concept as well as the first specialised literature originated (Boardman, 1991; Liddell et al., 2012; Roberts et al., 2015). However, few studies have been oriented towards the analysis of Mediterranean countries such as Spain, with socioeconomic and climatic conditions that are clearly different. Similarly, and in the current context, the analysis of energy poverty in Spain is particularly important, on the one hand because of the modification of the social tariff for electricity and the recent implementation of the social tariff for heating, and on the other because of the recent publication of the National Strategy to Combat Energy Poverty (ENCPE, 2019). Second, Spain is not a country with a homogeneous climate, and as such energy poverty should not be considered in the cold months only but also in the warmer months that are more frequent and more virulent every year due to the effects of climate change. With the aim of being able to identify the importance that climatic conditions may have for energy needs depending on the location of the home, information about the influence of extreme temperatures is included at a regional level. Finally, the econometric analysis in the literature has been mainly based on small cross-section samples potentially with conjunctural bias. In this study the use of a wide and recent time period (2011-2017) not only allows a photograph to be taken of energy poverty in Spain at a specific moment, but to go one step further by providing a structural view of the problem to be dealt with.

After this general introduction, the remainder of the paper is divided up in the following way. In section 2 a panoramic synthesis of energy poverty is presented. Section 3 describes the data base, the variables and the econometric methods used that allow the quantification, description and identification of the determinants of energy poverty in Spain. Then, the main empirical results are provided in section 4, and finally in section 5 the main conclusions are presented and public policy recommendations to combat energy poverty are put forward. 


\section{Scope of the analysis of energy poverty}

The identification of a problem necessarily requires it to be defined and measured. While energy poverty has been named and defined in general terms since the beginning of the eighties, it was not defined precisely until 1991 when Brenda Boardman stated it included those households where expenditure on energy exceeded $10 \%$ of their income (Boardman, 1991). This definition based on income and patterns of household energy expenditure is the starting point of a solid branch of academic literature that in the last quarter-century has elaborated various indicators in seeking to improve the identification and quantification of energy poverty, basically applying them to developed countries, and particularly to European countries, for their evaluation (Bouzarovski et al., 2012; Thomson and Snell, 2013; Burlinson et. al., 2018).

At the moment, in spite of there not being any absolute consensus about the best instruments for the analysis of energy poverty, it is possible to affirm that there is a subset of indicators that, from the perspective of incomes, allows the problem to be robustly quantified, and therefore, ultimately, solutions to be put forward for public policy. This subset is made up of the indicators that are most frequently used in the literature and which have been those favoured mainly by the United Kingdom government. However, in recent years they have also gained ground in research based in the EU (Legendre and Ricci, 2015; Bouzarovski and Tirado Herrero, 2017).

Among the indicators that analyse energy poverty from the perspective of incomes and which are most commonly used are: the ' $10 \%$ ' or similar approaches such as ' $2 \mathrm{M}$ ', that are based on the portion of income required to cover energy expenditure, the 'Minimum Income Standard' (MIS) (Moore, 2012) based on the minimum income necessary to cover energy costs once all other expenditure has been met, and the so-called 'Low Income High Cost' - LIHC - that concentrates part of the analysis on low income households when studying energy poverty and in this way allows an approach from the perspective of poverty in general (Hills, 2011, 2012). This solution is an improvement on other indicators that do not exclude high income households, such as the $10 \%$. With these it has been found - generally with the $10 \%$ but also with the MIS - that a significant number 
of households with relatively high incomes are energy poor, even though they should be able to absorb the cost of the highest energy bills ${ }^{4}$.

Measurement through the LIHC is not free of criticisms. One of the issues frequently pointed out is that, since the indicator defines poverty as those who earn $60 \%$ of median income in combination with the median energy cost (instead of $60 \%$ of the median energy cost), this approach excludes single person households (Broadman, B., 2012 and Robinson et. al., 2018). In the analysis performed here, this limitation is overcome by using the $60 \%$ of the median for both, income and energy expenditure. It is also claimed that the LIHC indicator tends to prioritise energy efficiency as a solution to fuel poverty, distracting from other drivers more related to affordability (Middlemiss, L. 2016). This is not a major source of concern given that the nature of our study is beyond the simple statistical analysis of the indicator, with the identification of causal relationships through the use of econometric techniques, including both income and expenditure side determinants.

As pointed out by Hills (2011), no indicator of a problem such as energy poverty is likely to be perfect, but the LIHC includes those on the margin of poverty who are pushed to energy poverty by their high energy requirement, hence considering the problem from both income and cost perspectives. Grounded on the above but acknowledging the limitations of using the LIHC as a single measurement, this study relies on a modified LIHC indicator to quantify the energy poverty in Spain.

Once energy poverty is quantified the next stage of the analysis concerns its causes. It is generally recognised in the literature that energy poverty arises from the combination of three main factors: low household incomes, high energy expenditure and inefficiency in homes (Lampietti and Meyer, 2002; Buzar, 2016). Generalisation is very useful as a starting point for any analysis of the subject. However, in order to obtain solid conclusions about the causes of energy poverty it is imperative to carry out a detailed robust analysis that allows the relative importance of each determinant to be quantified in the specific context of the country and/or region in which it is the intention to introduce proposals to mitigate or eradicate its effects.

\footnotetext{
${ }^{4}$ See Table B for greater detail about the advantages and disadvantages of the energy poverty indicators based on incomes.
} 
Academic analysis intended to define the determinants of energy poverty using econometric techniques from which it is possible to identify and estimate causal relations, is scarce. The econometric analysis of Legendre and Ricci (2015) carried out in France is a good example of the evaluation of the influence of demographic, socioeconomic and physical factors on the probability that a household will be in a situation of energy poverty. In particular, its results indicate that the probability of being energy vulnerable is greater for retired people who live alone, rent their house, cook with butane gas, use an individual boiler for heating and have deficient insulation.

Concerning Spain in particular, it is worthwhile noting the study by Romero et. al (2018) that, in spite of having the objective of calculating and analysing different indicators of energy poverty applied to Spain, presents a brief econometric analysis for the year 2015 . Their results underline the importance of the structure of the household, the type of occupation of the home and the level of education. In the empirical study presented here previous results are used as a starting point, but the previous studies are improved upon with the analysis of a longer and more recent time period - the seven years between 2011 and 2017 - and with the inclusion of climatic variables to control for the geographical component.

There also exist studies that do not seek to identify energy poverty determinants but, for example, to explore the dynamics of energy poverty in Spain, and present statistical analyses in which the characteristics of the general population are compared with the energy poor (for example Phimister et. al., 2015). Despite not dealing with causal relations, statistical observations throw considerable light on the potential determinants of energy poverty in Spain, such as factors connected with the structure of the household, the level of education and the work situation. These elements coincide with some of those mentioned in Romero et. al (2018), for which reason they are included, among others, in the present study.

The main novelty of this empirical analysis consists in that, in addition to identifying the determinants of energy poverty over a long and very recent period, the effects related with each of these determinants at a national level are quantified. Finally, based on the results on the relative effects of the determinants, recommendations are presented for public policies to reduce the incidence of energy poverty. 


\section{Data and model specification}

\subsection{Data}

The data base used in this study is drawn from two sources of information, the Household Budget Survey (HBS) and extreme temperatures at the regional level. The HBS is carried out by the National Statistics Institute annually and contains detailed information about consumer spending in approximately 24,000 Spanish households per year. Specifically, the data base used in the empirical analysis carried out is made up of a total of 151,638 Spanish households - 21,662 per year on average ${ }^{5}$ - and covers the period 2011-2017. ${ }^{6}$

Among the various expenditures per household it includes an essential variable for this study, the expenditure on energy (electricity, liquid gas, natural gas, combustible liquids and solid fuels in the main home). Additionally, this statistical source provides complete information about a set of variables related with the living conditions in households of great importance for the study of the determinants of energy poverty (from characteristics related to the household and the home, to information about household incomes).

The households that actively collaborated for a period of 14 days by participating in interviews and directly taking notes on all their spending stayed in the sample for two consecutive years and were replaced by similar households to maintain relevance at a national as well as a regional level. In order to obtain significant results from this set of microdata, the results of this study were calculated taking spatial elevation factors provided by the National Statistics Institute into account. These factors of spatial elevation allow us to obtain representative results for Spanish households.

In addition, and with the purpose of identifying the importance that climatic conditions may have for energy poverty depending on the location of the home, the final data base also included information at a regional (NUTS 2) level about the incidence of extreme temperatures. Specifically, the variations in temperature can be calculated through the sum of the differences in temperature between a certain constant interior temperature and

\footnotetext{
${ }^{5}$ Among the main filters applied to the sample should be underlined the elimination of those households with omitted values in the important variables or extreme values (outliers) that can distort the behaviour of the sample.

${ }^{6}$ Despite the data base containing information since 2006 data from 2011 onwards is used in the empirical analysis as this was the last year of important changes in the survey, in order to guarantee the perfect homogeneity of the information. Among the changes implemented after 2011 stand out, because of their importance, the introduction and/or modification of some variables, and the separation of the information for Ceuta and Melilla, as previously these were gathered and reported jointly.
} 
the daily average of the exterior temperature. These indicators, published by Eurostat, are known as heating degree days (HDD) and cooling degree days (CDD) ${ }^{7}$. The first indicator measures the severity of cold for a certain period of time in a region, while the second measures the severity of heat. These two measurements reflect the influence of climate on energy consumption.

\subsection{Calculation of the energy poverty indicator}

As we have seen in the previous section, there currently exist various ways to calculate energy poverty. The diversity of the indicators, each one with its advantages and disadvantages, leads at the same time to a variety of results that can make it difficult to achieve the final objective of this study, which is to approach the subject from an income perspective. Within this framework and given the impracticability of using multiple indicators, the indicator Low Income High Cost (LIHC) was chosen as the most appropriate indicator for describing and quantifying energy poverty in Spain.

This indicator was proposed for the first time by Hills (2012) and solved some of the limitations of the $10 \%$ or the MIS indicators. According to Hills' indicator, a household is defined as energy poor if its income is below a certain poverty threshold and its expenditure on energy is above an energy threshold.

Following the recommendations of Eurostat, the poverty line is set in this study at $60 \%$ of median income. In particular, for calculating the indicator the equivalent income of the household is used in order to take into account the influence of the number of its members on the level of income necessary for the household not to be in a vulnerable situation. On the other hand, according to Hills (2012) the threshold for energy expenditure is defined as the median equivalent of energy expenditure calculated for all of the households.

The definition of both these thresholds is not a simple task, and no decision will be exempt from criticism. The main advantage of this indicator is that apart from expenditure on energy, and unlike the $10 \%$ indicator, it takes the level of household income into account. In this way high income households with high energy consumption preferences are not identified as energy poor. Its main disadvantage is that it is relatively difficult to calculate and explain. As it considers two conditions for a household to be classified as poor it adds

\footnotetext{
${ }^{7}$ See https://www.eea.europa.eu/data-and-maps/indicators/heating-degree-days/assessment
} 
a level of complexity that entails difficulties in explaining its elaboration to the public in general. Finally, greater rigour is required compared to the other indicators in order to analyse variations in the values of energy poverty.

At any event this indicator fulfils the characteristics sought after in this study. On the one hand it considers the income and consumption of energy in households and, on the other, it is sufficiently stable for the values not to become affected by factors unconnected with income or energy consumption. In this way it facilitates the design of public policies directed at mitigating the problem of energy poverty from either the income or the expenditure side.

Specifically, a household is energy poor if it fulfils the two following conditions: ${ }^{8}$

$$
\begin{array}{lr}
E E_{i t}>\widetilde{E E}_{t} & \text { Eq. } 1 \\
\text { Inc }_{i t}-E E_{i t}<60 \% *\left(\widetilde{I n} c_{t}-\widetilde{E E}_{t}\right) & \text { Eq. } 2
\end{array}
$$

where:

$E E_{i t}$ is the energy expenditure of household $i$ in period $t$

$\widetilde{E E}_{t}$ is the country median energy expenditure in period $t$

$I n c_{i t}$ is the income of household $i$ in period $t$

$\widetilde{I n} c_{t}$ is the country median income in period $t$

In order to calculate the indicator LIHC a measurement of income is necessary, as well as of expenditure on energy, for each household. The net income was calculated annualising the total monthly net incomes of the households, while the expenditure on energy of the household takes the annual expenditure on the following categories into account, only considering the principal residence. ${ }^{9}$

- Electricity: expenditure on electrical energy, contract charges for light, renting and reading of meters.

\footnotetext{
${ }^{8}$ Following Romero et al. (2018), from the initial approach of Hills (2012) the median of energy expenditure is subtracted from the median household income to be consistent with the first term of the equation. In addition, with this formulation we also overcome the main criticism of Robinson et. al. 2019 (mentioned in section 2) regarding the consideration of the median fuel cost instead of the $60 \%$ of the median as in the case if the income.

${ }^{9}$ Expenditure on communal heating and hot water, steam and ice have not been included in the annual computation of expenditure on energy as they represent a very residual part of total expenditure (less than $0.08 \%$ of the total).
} 
- Town and natural gas: expenditure on town gas and natural gas, gas contract charges, renting and reading of meters.

- Liquefied petroleum gas: expenditure on butane and propane gas, renting and reading of meters, bottles and containers for these gases.

- Combustible liquids, expenditure on heating oil, fuel oil, lamp oil and other combustible liquids, contract charges, renting and reading of meters.

- Solid fuels, expenditure on coal, coke, coal agglomerations, wood, vegetable coal, and peat.

According to the indicator LIHC, on average, $8.3 \%$ of Spanish households were in a situation of energy poverty during the period 2011-2017 (Graph 1). This figure indicates that it is not a minor problem, once again demonstrating the importance of establishing a national strategy to fight against it. Taking the time span of this indicator into account it is possible to identify two different periods of developing trends closely related with the economic growth of the country (measured in terms of Gross Domestic Product (GDP)). The first period, characterised by a steady increase in the rate of energy poverty goes from 2011 until 2013, reaching its maximum peak in the last year $-9.0 \%-$. This trend could be explained by the effect of the economic crisis (GDP growth deceleration) added to a notable increase in the price of energy. On the other hand, from 2013 onwards, once the economy gradually begins to recover, a clear gradual decrease can be seen in the energy poverty rate in Spanish households, arriving at the minimum value in 2017 of $7.4 \%$ of the total population in a vulnerable situation.

\section{INSERT GRAPH 1 HERE}

\subsection{Empirical strategy}

To examine the probability that a household is in a situation of energy poverty a discrete choice univariate probit model was used, as it is considered the most suitable for this kind of estimation. In order to do this a dichotomous dependent variable was constructed $\left(Y_{i t}\right)$ that takes the value 1 when a Spanish household is in a situation of energy poverty according to the LIHC indicator and 0 when a household is not considered to be energy poor. 
The specification used was as follows:

$$
\begin{aligned}
& \operatorname{Pr}\left(Y_{i t}=\text { Energy poor } \mid X\right) \\
& =\Phi\left(\beta_{0}+\delta_{1} \text { rural }_{i t}+\delta_{2} \text { old home }\right. \text { hit } \\
& +\delta_{3} \text { apartment building }_{i t}+\delta_{4} \text { núm.rooms } \text { rt }_{i t} \\
& +\delta_{5} \text { one person }_{i t}+\delta_{6} \text { one parent }_{i t}+\delta_{7} \text { unemployed } \quad \text { Eq. } 3 \\
& +\delta_{8} \text { higher education }+\beta_{9} \text { rented property } \text { it } \\
& +\beta_{10} \operatorname{Ln}\left(\text { degrees }- \text { heating days }{ }_{i t}\right) \\
& \left.+\beta_{11} \operatorname{Ln}(\text { degrees }- \text { days of cooling } \text { it })+\tau_{1} \text { Year }_{t}+\varepsilon_{i}\right)
\end{aligned}
$$

where Pr stands for probability, the vector of explaining variables $(X)$ contains a set of variables that determine whether a home is considered to be energy poor, $\beta$ corresponds to the vector of coefficients to be estimated and reports the effect of a variable on the latent propensity for a positive result, $\Phi$ is the cumulative distribution function of the standard normal distribution, and finally, $\varepsilon_{i}$ is the idiosyncratic error term. In particular, in order to capture the multifaceted nature of energy poverty we include a set of independent variables that the empirical literature lists as determinants of energy poverty in capturing factors related to: (1) characteristics of the home such as whether the home is located in a rural area or not, whether the home was constructed 25 or more years ago, and whether the building in which the home is located contains more than one dwelling, (2) characteristics of the household such as whether the household comprises one person or not and whether the household is composed of a one-parent family, (3) income and wealth factors regarding the employment and education situation of the main breadwinner and whether the home occupied is rented, and finally, (4) climatic conditions showing the extreme temperatures (Table 1). ${ }^{10}$ This approach allow us to identify not only economic drivers, but also energy efficiency and climatic factors covering multiple aspects of energy poverty. In addition, a set of time dummies have been included in all the

\footnotetext{
10 After an in-depth analysis of the multiple variables available in the HBS and taking the economic literature that deals with energy poverty into account, a selection of the explaining variables was made in accordance with the context of Spain, with the purpose of approaching the reality of the country better and more closely. Similarly, following the procedure of progressive elimination (Backward Stepwise Regression) those explaining variables that are less influential according to the individual contrast have not been included in the final regressions of the present study.
} 
regressions to control, for example, for the possible effects of the economic, social and climatic cycles.

Since coefficient estimates of probit models $(\beta)$ cannot be interpreted as straightforwardly we also report the marginal effects (Hamner and Kalkan, 2013). ${ }^{11}$ While the coefficients of the binary models give information about the effect of the variable on the latent propensity of a positive result - to be energy poor -or in other words, whether the explanatory variables are statistically significant or not, the values of the marginal effects show the real impact of each explanatory variable on the probability of being in an energy vulnerable situation, which is substantially of much more interest.

\section{INSERT TABLE 1 HERE}

\section{Results and discussion}

This section presents the results obtained through the estimation of the econometric probit model (Table 2) and the marginal effects are reported to improve interpretation (Table 3). While Table 2 indicates the significance and sign of each determinant of energy poverty in Spain, the values of the marginal effects from Table 3 provide the real impact of every explanatory variable on the probability of being in an energy vulnerable situation.

The results suggest that the intrinsic characteristics of Spanish homes significantly affect the probability of a household being energy poor. In particular, the probability of suffering problems of energy poverty increases by 2.4 percentage points when a home is located in a rural area. The fact that in these rural areas there is greater vulnerability could be for various reasons such as, for example, the availability of different combustible materials with different prices in these areas, or the presence of high proportions of large

\footnotetext{
11 The marginal effect of a variable $x_{k}$ is obtained through the derivative of equation (3) with respect to $x_{k}:\left(\partial \rho / \partial\left(x_{k}\right)=f(x \beta) \beta k\right)$, where $f$ represents the probability density function. We directly address the computation of marginal effects for each explanatory variable using the probit post-estimation utility attached to the Stata probit command. In particular, the marginal effects are calculated for each case and then are averaged in all cases (average marginal effects).
} 
or isolated households with difficulties in maintaining adequate thermal temperatures, which finally means an increase in energy expenditure (Kaygusuz, K., 2010 provides an in depth analysis on the nature of energy poverty problems in the context of rural areas).

Similarly, the age of the home and the number of rooms indicate greater vulnerability, but their impact is slightly less (1.4 and 0.3 percentage points respectively). Nevertheless, active measures to encourage energy saving and energy efficiency are a priority in Spain, and it is important to mention that $50 \%$ of the housing stock in Spain was constructed before the 1980s, when the energy efficiency of homes was not contemplated in regulations governing buildings. With regard to the type of building in which the home is located the results indicate that the probability that a household is in a situation of energy poverty decreases by nearly 3 percentage points when Spanish families live in an apartment block, as opposed to detached or individual terraced family homes.

The composition of the household also has a great influence on the probability that a household will be energy poor. Households made up of only one person show greater probability - 6 percentage points - of being diagnosed energy poor. A possible explanation for this phenomenon is that, in general, these are individuals with lower household incomes and, because of that, greater economic difficulties in paying essential bills, and among those bills for energy consumption.

Equally one-parent homes with responsibility for minors have a significant positive effect associated in the probability of being energy poor (with a 7.2 percentage points increase). In recent years the composition of Spanish households has undergone considerable changes, with new family units appearing among which one-parent families stand out. In this sense it is of vital importance to capture the socioeconomic reality of the moment in Spain in this type of study. This family composition model, mainly headed by a woman and, consequently, with greater problems to reconcile family and working life, is particularly affected by energy poverty, among other factors of social exclusion.

A third set of key elements in the problem of energy poverty is connected with income levels and wealth. The probability that a household will be in a situation of energy poverty increases by 9.3 percentage points when the main income earner is unemployed. In fact, this variable, that captures the income levels of the household, has the greatest impact among all the variables analysed on the probability of being energy poor. 
Income levels are very related to levels of education. The results indicate that a higher level of education is closely related to a reduction of 7.8 percentage points in the probability of getting into a situation of energy poverty. Households with low and irregular incomes and a low educational level often live in poor-quality homes as they lack the necessary means to either know about and understand possible ameliorating measures - good saving practices, social support etc. - or to invest in energy efficiency improvements.

Another factor that aggravates the energy poverty situation is the type of occupation of the home. In particular, those Spanish households that sign a rent contract have a greater probability of being energy poor. The fact of living in homes where they are not the legal property owners is a disincentive to looking for solutions to improve the condition and the energy efficiency of the home, as much from the point of view of the owner as from the tenant.

Finally, another of the axes that determine energy poverty are the climatic variables. Although less strongly than with regard to the income and household composition variables, Spanish families that live in regions in which the climate temperatures are more extreme show a greater propensity to be energy poor. In more detail, the results show that the impact of extremely cold conditions affects energy vulnerability much more in comparison to extremely hot conditions.

\section{INSERT TABLE 2 AND 3 HERE}

To sum up, it can be clearly seen from the above results that the four variables unemployed, higher education, one-parent household and one-person household - with the greatest impact in Spain on the probability that a household will be energy poor are closely related to the income levels of the household. The results presented suggest that measures directed towards mitigating the problem of energy poverty in Spain will essentially have to take income and composition of the household into account.

Policies oriented towards mitigating unemployment include mainly unemployment subsides, which in Spain are always temporal and subject to the specific reality of the beneficiary. More attention could be devoted to active policies that allow the creation of new jobs or aid to companies for hiring the jobless, which may contribute to reducing 
unemployment and therefore the incidence of poverty in the population. In addition, when considering the level of education, policies should take into account that it effects energy poverty both directly and indirectly. The direct effect is exerted toward the widely proven influence that education has on personal and household income. Meanwhile, the indirect impact of education comes from its effect on the further development of skills to process highly complex information and understand difficult problems. This can significantly affect the behaviour of households making it difficult to understand all the elements linked to their consumption decisions, including energy consumption. Therefore, specific programs could be focused on consumers in homes without higher education, including measures aimed at improving awareness and information both on responsible consumption, and on their rights to access aid and the existent social tariffs.

Finally, it is relevant to highlight that although the impact of the characteristics of the home and the climatic variables -highly correlated with the level of energy efficiency of the homes-, is low in comparison with the income factors, energy efficiency actions cannot be set aside. Energy efficiency measures are a key element of the European policy to achieve cleaner, competitive and safe energy. Consequently, all the variables considered, with a higher or lower rank in terms of action priorities, are necessary to respond to the multifaceted nature of energy poverty.

\section{Conclusions and policy implications}

The economic crisis has exacerbated the difficulties suffered by European households. Among these problems, energy poverty stands out because of the growing concern among those with political responsibilities, academics and representatives of the third sector. Through the use of a representative sample of Spanish households in the period 20112017 this study presents an approach to the problem of energy poverty in Spain that includes the prominent importance of these considerations seen from the angle of household incomes. This approach contributes to the existing discussion about energy poverty through the economic analysis of the relation between energy poverty, energy consumption and elements connected to household incomes.

The econometric results indicate that the Spanish households most vulnerable to energy poverty are those where the principal wage-earner is unemployed, where the members have a lower educational level, and those which are formed by one person or also by one 
parent caring for a child or children. A close relationship can be clearly seen between household income and the probability of being in a situation of energy poverty. At the same time the results also suggest that the intrinsic characteristics of Spanish homes and climatic conditions significantly affect the probability of a household being energy poor, even though their impact is slightly less.

In the Energy Union Communication of 2015, the European Commission declared that energy poverty should be approached, preferably, through the general social welfare system, and that mechanisms for the protection of vulnerable consumers should be elaborated in the framework of the general welfare system (European Commission 2015). The results of this study reinforce this idea and underline the need for deep reflection on how to confront energy poverty with public policies of a transversal nature that, beyond elements directly related to energy policy, act on the main determinants of energy poverty, fundamentally connected, directly or indirectly, with household incomes.

Current Spanish policy proposes interesting modifications regarding the trend in previous times through the National Strategy to Combat Energy Poverty (ENCPE, 2019) with multiple axes and lines of action to achieve the objective of reducing energy poverty ${ }^{12}$. An interesting example is provided by the measures that are established to improve knowledge about energy poverty, including the implementation of a system that allows the periodic calculation of the indicators, accompanied by measures to ensure the transparency of information and the improvement of knowledge of the energy expenditure needs of homes. This could be enriched by conducting regional analyses in which the determinants of energy poverty are evaluated in depth, as we propose to do in future research and for a greater number of indicators. In addition, it could also improve knowledge about the vital reality of households (including socioeconomic conditions), relevant for the effect it has on their vulnerability to the situation of energy poverty and the consequences it has for its inhabitants.

Despite the recent improvements that ENCPE poses, there is still potential to improve policies to address energy poverty. As an example, linked to the actions seeking to improve the response to the current energy poverty problem, as in the recent inclusion of income level limits for pensioners within the conditions of access to the social tariff, an

\footnotetext{
12 The actions axes and lines are summarized in Table B.
} 
income limit for large families could also be included. In any case some correction factor by number of members in the family unit must be incorporated, but ultimately it should be a guarantee that the aid reaches the homes that really need it.

Additionally, it should be noted that it would also be convenient to homogenize the financing source of the current benefits (the electricity and heating social tariffs). In the first case, the burden of the cost of the electricity tariff is borne by energy companies instead of public budgets, as in the case of the heating tariff. It would be better to use the latter source of finance for both. It would also be more efficient to have a single energy tariff that covers all energy needs processed by a public agency. By this means the transaction costs for the processing of the aid would significantly decrease, given that the multiple documents and forms that consumers have to collect and deliver at present are already in the hands of the administration.

As well as all the measures that can be applied on the income side, there are policies focused on tackling energy poverty that act on the the expenditure side of households. Particularly worth mentioning are those containing actions to improve the energy efficiency of homes.

In spite of these conclusions, we are aware of the main limitations of this study, though these are at the same time opportunities for further research. In the first place, although the main data base used in this study is a source of valuable data used in different analyses of energy poverty in Spain, it was not specifically designed to examine the problem of energy poverty. We should therefore be aware that variables of interest in examining the vulnerability of Spanish households, such as the type of domestic appliances used and their consumption, energy efficiency measures carried out and whether households have access to some type of subsidy in energy matters, are not available.

Finally, our research has concentrated on the identification and description of energy poverty at a national level and in future studies this analysis can be deepened through its application at a regional level. Given the economic, geographical, climatic and social disparities in the whole of Spain, detailing smaller geographical areas would help to provide more specific empirical evidence and could lead to a broader and deeper understanding of the factors that influence energy poverty. This, in turn, could improve the adaptation of policies to the intrinsic characteristics of each region in question. 


\section{Acknowledgement}

We acknowledge financial support from the Chair of Energy Sustainability (IEB, University of Barcelona), Naturgy Foundation, FUNSEAM and from the projects ECO2015-69107-R (MINECO / FEDER, EU) and 2017-SGR-739 (Government of Catalonia).

\section{Appendix}

\section{INSERT TABLE A HERE}

\section{References}

Besagni, G., Borgarello, M. (2019). The Socio-Demographic and Geographical Dimensions of Fuel Poverty in Italy.” Energy Research and Social Science, 49: 192-203. Boardman, B. (1991). Fuel poverty: from cold homes to affordable warmth. Belhaven Press, London.

Broadman, B. (2012). Fuel poverty synthesis: lesson learnt, actions needed. Energy Policy, 49: 143-148.

Bouzarovski, S., Petrova, S., Sarlamanov, R. (2012). Energy poverty policies in the EU: a critical perspective. Energy Policy 49: 76-82.

Burlinson, A., Giulietti, M., Battisti, G. (2018). The elephant in the energy room: Establishing the nexus between housing poverty and fuel poverty. Energy Economics, 72: 135-144.

Buzar, S. (2016). Energy poverty in Eastern Europe: hidden geographies of deprivation. Routledge.

DECC, 2016. Annual fuel poverty statistics report.

ENCPE (2019). Estrategia Nacional Contra la Pobreza Energética. Ministerio para la Transición Ecológica, 04/03/2019. Available in:

https://www.miteco.gob.es/es/prensa/estrategianacionalcontralapobrezaenergetica20192024_tcm30-496282.pdf 
Hamner, M.J., Kalkan, K.O. (2013). Behind the curve: clarifying the best approach to calculating predicted probabilities and marginal effects from limited dependent variable models. American Journal of Political Science, 57 (1): 263-277.

Healy, J. (2003). Fuel poverty and policy in Ireland and the European Union Studies in Public Policy 12, Policy Institute at Trinity College.

Hills, J. (2011). Fuel poverty: the problem and its measurement. London, United Kingdom: Centre for Analysis of Social Exclusion.

Hills, J. (2012). Getting the measure of fuel poverty. London, United Kingdom: Centre for Analysis of Social Exclusion.

Kaygusuz, K. (2010). Energy Services and Energy Poverty for Rural Regions, Energy Sources, Part B: Economics, Planning, and Policy, 5:4, 424-433.

Lakatos, E. and Arsenopoulos, A (2019). Investigating EU financial instruments to tackle energy poverty in households: A SWOT analysis, Energy Sources, Part B: Economics, Planning, and Policy, 1-19. DOI: 10.1080/15567249.2019.1667456

Lampietti, J., Meyer, A. (2002). When Heat is a Luxury: Helping the Urban Poor of Europe and Central Asia Cope with the Cold. World Bank, Washington, D.C.

Legendre, B. y Ricci, O. (2015). Measuring fuel poverty in France: which households are the most fuel vulnerable? Energy Economics, 49: 620-628.

Liddell, C., Morris,C,. Mckenzie, S. J. P., Rae. G. (2012). Measuring and Monitoring Fuel Poverty in the UK: National and Regional Perspectives. Energy Policy 49: 27-32.

Middlemiss, L. (2016). A critical analysis of the new politics of fuel poverty in England, Critical Social Policy, 37 (3): 425-443.

Moore, R. (2012). Definitions of fuel poverty: implications for policy. Energy Policy 49: $19-26$.

Papada, L., Kaliampakos, D. (2018). A Stochastic Model for Energy Poverty Analysis." Energy Policy, 116: 153-64.

Phimister, E., Vera-Toscano, E., Roberts, D. (2015). The Dynamics of Energy Poverty: Evidence from Spain. Economics of Energy \& Environmental Policy, 4(1): 153-166. 
Pye, S., Dobbins, A., Baffert, C., Brajkovi, J., Grgurev, I., De Miglio, R., Deane, P. (2015). Energy Poverty and Vulnerable Consumers in the Energy Sector across the EU: Analysis of Policies and Measures, Brussels (Policy Report, 2).

Roberts, D., Vera-Toscano, E., Phimister, E. (2015). Fuel poverty in the UK: is there a difference between rural and urban areas? Energy Policy 87: 216-223.

Robinson, C., Bouzarovski, S., Lindley, S. (2018). Getting the measure of fuel poverty: The geography of fuel poverty indicators in England. Energy Research \& Social Science, 36: 79-93.

Romero, J. C., Linares, P. López-Otero, X. (2018). The policy implications of energy poverty indicators. Energy Economics, 115: 98-108.

Thomson, H., Snell, C. (2013). Quantifying the prevalence of fuel poverty across the European Union. Energy Policy 52: 563-572. 


\section{GRAPH 1}

EVOLUTION OF ENERGY POVERTY IN SPAIN (LIHC) AND GROWTH OF THE GROSS DOMESTIC PRODUCT (GDP)

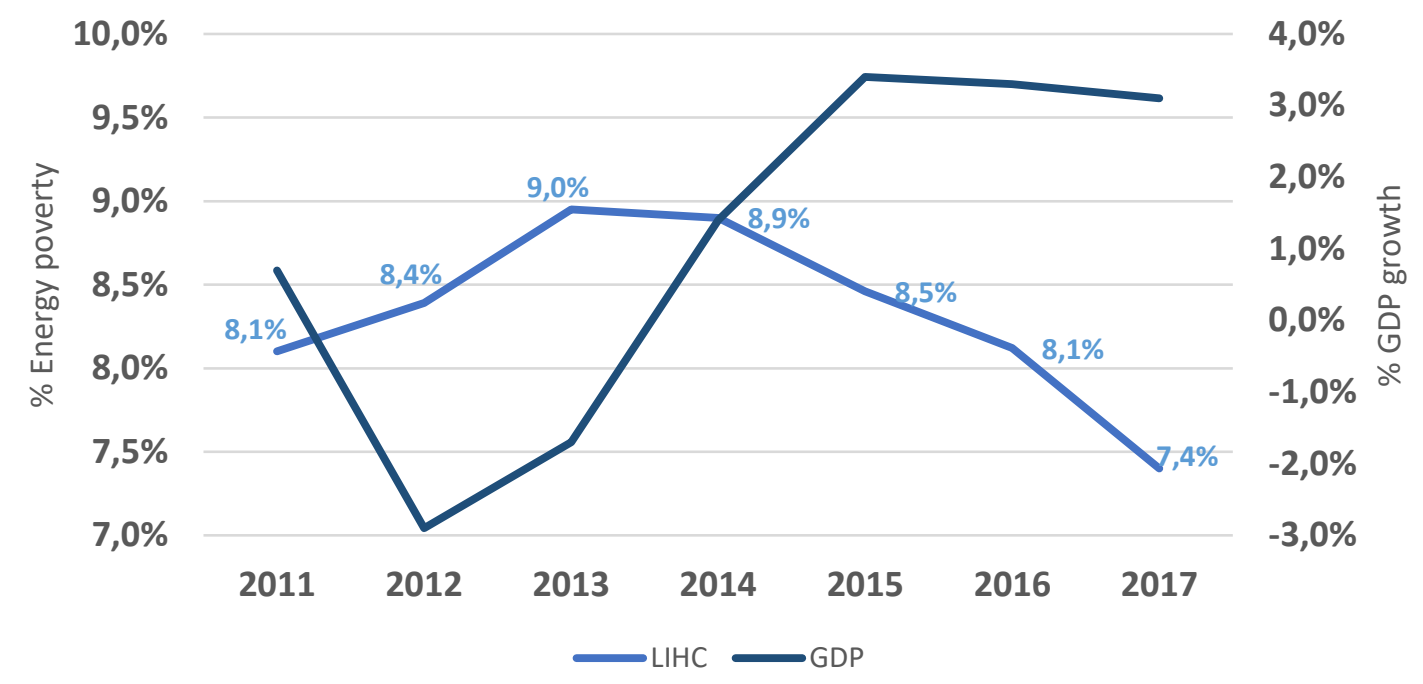

Source: Own elaboration from the HBS and Eurostat 
TABLE 1

DETERMINANTS OF ENERGY POVERTY

\section{Variable Definition of the variable $\quad \begin{array}{ll}\text { Expected } & \text { Mean }\end{array}$}

1. Characteristics of the home

\begin{tabular}{|c|c|c|c|}
\hline Rural & $\begin{array}{l}\text { Dichotomous variable that takes the value } 1 \\
\text { if the home is located in a rural area; } 0 \text { if not. }\end{array}$ & + & 0.1438 \\
\hline Old home & $\begin{array}{l}\text { Dichotomous variable that takes the value } 1 \\
\text { if the home was constructed } 25 \text { or more years } \\
\text { ago; } 0 \text { if not. }\end{array}$ & + & 0.6510 \\
\hline $\begin{array}{l}\text { Apartment } \\
\text { building }\end{array}$ & $\begin{array}{l}\text { Dichotomous variable that takes the value } 1 \\
\text { if the building in which the home is located } \\
\text { contains more than one home; } 0 \text { if not. }\end{array}$ & - & 0.6712 \\
\hline $\begin{array}{l}\text { Number of } \\
\text { rooms }\end{array}$ & Number of rooms the home contains. & + & 5.0335 \\
\hline
\end{tabular}

\section{Characteristics of the household}

\begin{tabular}{llcc}
\hline $\begin{array}{l}\text { One-person } \\
\text { household }\end{array}$ & $\begin{array}{l}\text { Dichotomous variable that takes the value 1 } \\
\text { if the household comprises one person; 0 if } \\
\text { not. }\end{array}$ & $+\mathbf{+}$ & 0.2410 \\
\hline $\begin{array}{l}\text { One-parent } \\
\text { household }\end{array}$ & $\begin{array}{l}\text { Dichotomous variable that takes the value 1 } \\
\text { if the household comprises one parent and at } \\
\text { least one child in her/his care; 0 if not. }\end{array}$ & + & 0.0269 \\
\hline
\end{tabular}

\section{Income and wealth}

\begin{tabular}{llll}
\hline Unemployed & $\begin{array}{l}\text { Dichotomous variable that takes the value 1 } \\
\text { if the main wage-earner in the household has } \\
\text { no paid employment or independent } \\
\text { employment is currently seeking } \\
\text { employment and is available for work; 0 if } \\
\text { not. }\end{array}$ & 0.0838 \\
\hline $\begin{array}{l}\text { Higher } \\
\text { education }\end{array}$ & $\begin{array}{l}\text { Dichotomous variable that takes the value 1 } \\
\text { if the main wage-earner has a higher } \\
\text { education (University education and/or } \\
\text { higher level professional or technical } \\
\text { training); 0 if not. }\end{array}$ & \\
\hline $\begin{array}{l}\text { Rented } \\
\text { property }\end{array}$ & $\begin{array}{l}\text { Dichotomous variable that takes the value 1 } \\
\text { if the home occupied is rented; 0 if not. }\end{array}$ & \\
\hline
\end{tabular}

\section{Climatic conditions}

\begin{tabular}{lll}
\hline $\begin{array}{l}\text { Degrees-days } \\
\text { of heating }\end{array}$ & $\begin{array}{l}\text { Naperian logarithm of the annual regional } \\
\text { values of the Degrees-days indicator of } \\
\text { heating. }\end{array}$ & $+\underset{+}{7.2328}$ \\
\hline $\begin{array}{l}\text { Degrees-days } \\
\text { of cooling }\end{array}$ & $\begin{array}{l}\text { Naperian logarithm of the annual regional } \\
\text { values of the Degrees-days indicator of } \\
\text { cooling. }\end{array}$ & $+\mathbf{+}$ \\
\hline
\end{tabular}

Note: Expected effect indicates the expected sign of each variable on the probability that a household is vulnerable according to the empirical literature (Section 2). Mean is the average of each variable for the period 2011-2017. Total observations: 151,683.

Source: Own elaboration 
PROBIT MODEL RESULTS. DETERMINANTS OF ENERGY POVERTY

\section{IN SPAIN}

Variables

LIHC

Characteristics of the home

Rural

$0.174 * * *$

Old home

(0.016)

$0.104 * * *$

Apartment building

$-0.210 * * *$

$(0.015)$

Number of rooms

$0.023 * * *$

(0.005)

Characteristics of the household

One-person

$0.428 * * *$

(0.014)

One-parent

$0.517 * * *$

(0.031)

Income and wealth

Unemployed

$0.668 * * *$

Education

$(0.018)$

$-0.562 * * *$

(0.016)

Rented property

$0.114 * * *$

(0.019)

Climatic conditions

Degrees-days of heating

$0.176^{* * *}$

Degrees-days of cooling

(0.014)

$0.045 * * *$

$(0.005)$

Constant

$-3.077 * * *$

(0.113)

151,683

Observations

Note: Robust standard errors in brackets. Level of significance $* * * \mathrm{p}<0.01, * * \mathrm{p}<0.05, * \mathrm{p}<0.1$. Estimation control for time dummies..

Source: Own elaboration 
TABLE 3

MARGINAL EFFECTS. DETERMINANTS OF ENERGY POVERTY IN SPAIN

Variables

Characteristics of the home

Rural

Old home

Apartment building

Number of rooms

Characteristics of the household

One-person

One-parent

Income and wealth

Unemployed

Education

Rented property

\section{Climatic conditions}

Degrees-days of heating

Degrees-days of cooling
Marginal effects

$$
\begin{gathered}
0.024 * * * \\
(0.002) \\
0.014 * * * \\
(0.002) \\
-0.029 * * * \\
(0.002) \\
0.003 * * * \\
(0.001)
\end{gathered}
$$

$0.060 * * *$

(0.002)

$0.072 * * *$

(0.004)

$0.093 * * *$

$(0.003)$

$-0.078 * * *$

(0.002)

$0.016^{* * *}$

(0.003)

$$
\begin{gathered}
0.025 * * * \\
(0.002) \\
0.006 * * * \\
(0.001)
\end{gathered}
$$

Observations 151,683

Note: Robust standard errors in brackets. Level of significance $* * * \mathrm{p}<0.01, * * \mathrm{p}<0.05, * \mathrm{p}<0.1$. The marginal effects are calculated for each case and then are averaged in all cases (average marginal effects). For dummy variables, change in probability for a discrete change of the dummy variable from 0 to 1 .

\section{Source: Own elaboration}


TABLE A

\section{Advantages and disadvantages of the main indicators}

\section{$10 \%$ Threshold}

$>$ Among its main advantages the clearest is its ease of calculation and communication. Its application in different countries and regions is very practical.

$>$ Its disadvantages also lie in the simplicity of its calculation. The two main criticisms usually made of this indicator are the arbitrariness of the choice of a threshold of $10 \%$ and that it does not consider the level of household income. Another of its disadvantages is that it is extremely sensitive to changes in the price of energy.

\section{MIS (Minimum Income Standard)}

$>$ The main advantage is that it includes the minimum household income necessary to cover basic needs.

$>$ The greatest difficulty there is in the calculation of this indicator is in being able to define a reasonable threshold of minimum income for every country.

$>$ In Spain, one possibility is to use the Minimum Integration Income, or Social Salary. However, this value lacks sufficient basis to be considered a valid measure, as its value depends on what regional administrations consider to be adequate and this fluctuates from one year to another due to political decisions not related with energy poverty.

\section{LIHC (Low Income High Cost)}

$>$ The main advantage of this indicator is that, unlike the $10 \%$ indicator, it takes the level of household income as well as spending on energy into account and therefore is focused on the lower part of income distribution.

$>$ Its main disadvantage is that it is relatively complicated to calculate and explain. As it considers two conditions for a household to be classified energy poor, it adds a level of complexity that brings with it difficulties in explaining how it works to the general public.

$>$ It is also claim that this indicator excludes single person households and tends to prioritise energy efficiency as a solution to fuel poverty, distracting to other drivers more related to the affordability. As highlighted in the main text, these are not a major source of concern given the methodological approach of this study. 
TABLE B

Axes and lines of action

\begin{tabular}{|c|c|}
\hline Axes & Lines \\
\hline \multicolumn{2}{|c|}{ Improvement of the energy poverty knowledge } \\
\hline \multicolumn{2}{|r|}{$\begin{array}{l}\text { * Establish a robust system for the periodic calculation of indicators and designate } \\
\text { responsible agencies } \\
\text { * Provide transparency to the system of publication of indicators } \\
\text { * In-depth knowledge of the energy expenditure required for different consumers }\end{array}$} \\
\hline \multicolumn{2}{|c|}{ To improve the response in front of the current energy poverty problem } \\
\hline \multicolumn{2}{|r|}{$\begin{array}{l}\text { * Improvement of subsidy mechanisms against energy poverty } \\
\text { * Consumer protection in extreme weather situations }\end{array}$} \\
\hline \multicolumn{2}{|c|}{ To create a structural change for the energy poverty reduction } \\
\hline \multicolumn{2}{|r|}{ * Decrease the number of people in energy poverty } \\
\hline \multicolumn{2}{|c|}{ Measures for consumer protection and social conscience } \\
\hline \multicolumn{2}{|r|}{$\begin{array}{l}\text { * Improvement of consumer information and training } \\
\text { * Regulatory improvements for consumer defence } \\
\text { * Improvement of subsidy mechanisms against energy poverty }\end{array}$} \\
\hline & Source: ENCPE, 2019 \\
\hline
\end{tabular}

